\title{
Body mass index and gestational weight gain in pregnant women with gestational diabetes and its relation with adverse maternal and fetal outcome
}

\author{
Abha Singh, Avinashi Kujur*, Archana Roy
}

Department of Obstetrics and Gynecology, Pt. J. N. M. Medical College, Raipur, Chhattisgarh, India

Received: 01 September 2020

Accepted: 16 September 2020

\section{*Correspondence:}

Dr. Avinashi Kujur,

E-mail: avinashikujur@gmail.com

Copyright: $\odot$ the author(s), publisher and licensee Medip Academy. This is an open-access article distributed under the terms of the Creative Commons Attribution Non-Commercial License, which permits unrestricted non-commercial use, distribution, and reproduction in any medium, provided the original work is properly cited.

\begin{abstract}
Background: Raised body mass index (BMI) and excessive gestational weight gain (GWG) are important determinants in development of gestational diabetes.

Methods: A prospective, observational study carried out on antenatal women since their first trimester. These women were screened for gestational diabetes mellitus (GDM) by diabetes in pregnancy study group of India (DIPSI) criteria. All participants were followed up by measuring their BMI, weight gain, blood sugars in every trimester. Also, data was collected regarding any adverse outcomes.

Results: Among all participants, $16.8 \%$ were diagnosed as GDM. 44\% women of study group had weight gain beyond Institute of Medicine (IOM) recommendations. Higher risk of GDM was observed in women with raised BMI and excessive GWG. Also, odds of preeclampsia, preterm deliveries, caesarean section, macrosomia, intrauterine fetal death, neonatal intensive care unit (NICU) admissions were higher in women with GDM.

Conclusions: Compliance of recommended weight gain during pregnancy have a strong impact on the fetal outcome. Amount and timing of weight gain plays a crucial role in GDM.
\end{abstract}

Keywords: Body mass index, Gestational diabetes mellitus, Gestational weight gain, Maternal and fetal outcome, Raised BMI, Pregnancy

\section{INTRODUCTION}

Gestational diabetes mellitus (GDM) is known to be associated with an increased risk of maternal and perinatal complications. This risk is not only in the immediate period but has a long-term risk of developing type 2 diabetes mellitus (DM) for the offspring. Maternal nutrition and gestational weight gain (GWG) are factors which can be modified to prevent adverse outcome. The developmental origins of health and disease hypothesis proposed a link between prenatal, intranatal and early postnatal exposure to certain dietary, and lifestyle factors and development of obesity and non-communicable diseases. ${ }^{1}$ GWG is a major predictor of obstetric, neonatal outcome and health later in life.
Pregnancy is a stressful condition, characterized by progressive insulin resistance. The weight gain is not constant but varies in different trimesters. Maternal weight gain early in pregnancy is only a disproportionate fat and it invites subsequent maternal insulin resistance. The GWG has been classified by Institute of Medicine (IOM) in 2009 based on World Health Organization (WHO) recommendations and adopted by National heart, lung and blood institute. ${ }^{2}$

We wanted to compare if the weight gain in our women is same as that recommended by IOM and to examine the association between gestational weight gain and the risk of GDM for women presenting in our antenatal outpatient department (OPD). 


\section{METHODS}

This observational, prospective and case control study was carried out on pregnant women attending the outpatient clinic of Obstetrics and Gynaecology department of Pt. J. N. M. Medical College and DRBRAM Hospital, Raipur Chhattisgarh during study period of one year from 01 June 2017 to 31 May 2018. After informed and written consent, pregnant women fulfilling the inclusion criteria were screened and recruited for the study. Necessary demographic data was collected. At first visit height and weight was measured using the standard departmental protocol and BMI was calculated by formula. Then the women were classified according to WHO classification for BMI: BMI less than $18.5 \mathrm{~kg} / \mathrm{m}^{2}$ as underweight, BMI 18.5-24.9 as normal, BMI 25-29.9 as overweight and BMI more than $30 \mathrm{~kg} / \mathrm{m} 2$ as obese. Adequacy or inadequacy in weight gain was defined according to IOM recommendations. ${ }^{3}$

Oral glucose challenge test (OGCT) using single step method following diabetes in pregnancy study group of India (DIPSI) guidelines was done in every registered patient. ${ }^{4}$ If the woman tested positive, she was labelled as gestational diabetes and was enrolled in study group. Those with negative results were labelled as non GDM and enrolled in control group. Weight and BMI were measured in every trimester. OGCT was repeated at 24-28 weeks of gestation. Those with positive results at 24-28 weeks were deleted from the study. Follow up of both groups was done throughout the pregnancy to look for development of any maternal or foetal complications and at the end, outcome was noted. All the women were tested and managed according to guidelines for management of GDM by Ministry of health and family welfare, Government of India. $^{5}$

\section{Inclusion criteria}

Pregnant women with singleton pregnancy coming in first trimester and showing positive test after OGCT were included in the study.

\section{Exclusion criteria}

Women with pre-existing diabetes, women who tested positive at 24-28 weeks of pregnancy, women with medical disorders like thyroid disorder, chronic hypertension, multiple pregnancy, heart disease and those on steroid therapy were excluded.

\section{Statistical analysis}

All the relevant data was collected as per performa and tabulated in Microsoft excel sheet 2019 and was analyzed using Statistical Package for the Social Sciences (SPSS) version 20. Student's unpaired t test was used for analysis of continuous variables whereas the categorical variables were analyzed by Chi square test with $p \leq 0.05$ considered as significant.

\section{RESULTS}

In the study period of one year, 30601 patients attended antenatal OPD in 1st trimester of pregnancy. 1813 women fulfilled the inclusion criteria and were enrolled. 178 were lost to follow up or were deleted from study later. Table 1 shows the characteristics of study group. Majority of women with GDM were primigravida $(83.2 \%)$. Positive family history was found in $27.7 \%$ of women in study group and is almost half $15.7 \%$ in control group.

Table 1: Demographic characteristics of women in study and control group.

\begin{tabular}{|l|l|l|}
\hline Characteristics & $\begin{array}{l}\text { Study group } \\
(\mathbf{n = 2 7 5})(\%)\end{array}$ & $\begin{array}{l}\text { Control group } \\
(\mathbf{n}=\mathbf{1 3 6 0})(\%)\end{array}$ \\
\hline $\begin{array}{l}\text { Age in years } \\
\text { (mean } \pm \text { 2SD) }\end{array}$ & $29.1 \pm 1.2$ & $24.3 \pm 1.1$ \\
\hline Gravida & & 88.7 \\
\hline Primigravida & 83.2 & 11.2 \\
\hline Multigravida & 16.7 & 15.7 \\
\hline $\begin{array}{l}\text { Positive family } \\
\text { history }\end{array}$ & 27.7 & \\
\hline Gestational age at delivery (weeks) & 2.2 \\
\hline 15-24 & 11.1 & 4.4 \\
\hline $25-29$ & 5.5 & 7.8 \\
\hline $30-34$ & 5.5 & 73 \\
\hline $35-40$ & 22.2 & 12.3 \\
\hline$>40$ & 33.3 & 24.4 \\
\hline Mode of delivery & & 75.6 \\
\hline LSCS & 66.6 & 11.1 \\
\hline Vaginal & 11.1 & $2.5 \pm 0.05$ \\
\hline Abortions & $3.5 \pm 0.259$ & \\
\hline $\begin{array}{l}\text { Baby weight in } \\
\text { kg (mean } \pm 2 S D)\end{array}$ & & \\
\hline
\end{tabular}

The prevalence of GDM in our set up was $16.8 \%$. Women who exceeded IOM guidelines had a significant increase in GDM in $66.6 \%$ overweight group and $50 \%$ in obese group. Most of the current evidence of GWG is through western studies. Our state Chhattisgarh is a relatively newer state of India showing rapid development in all spheres with a constant increase in gross domestic product (GDP) at $5.32 \%$ (Table 2).

Table 3 shows GWG according to IOM. In our women $64.46 \%$ women in study group had normal weight gain and $20.55 \%$ of all women had inadequate weight gain. Our results almost agree with National Family Health Survey4, 2015-2016 (NHFS-4) for the underweight group, where it has been noted to be $22.9 \%$. However, they reported a rise in overweight and obese group from $12.6 \%$ (NFHS-3, 2005-2006) to 20\%, which has not been observed in our study. We found a lower prevalence of $11.19 \%$ of GDM in overweight group and only $3.79 \%$ in obese group. ${ }^{2}$

Table 3 shows GWG with significant difference in adequate weight gain group. This is very important in that only $4.6 \%$ women in study group had normal weight gain 
according to IOM recommendations, whereas $95.3 \%$ in the control group had adequate weight gain. The complications of pregnancy except preterm were more frequent in the study group as seen in Table 4. There was a significant difference in admission of neonates to the nursery. Almost $50 \%$ babies were admitted in neonatal intensive care unit as against only $1.1 \%$ in the control group.

Table 2: Gestational weight gain according to IOM recommendations.

\begin{tabular}{|lllllll|}
\hline BMI & $\begin{array}{l}\text { Total no. } \\
\text { of women }\end{array}$ & $\begin{array}{l}\text { Women in } \\
\text { study group }\end{array}$ & $\begin{array}{l}\text { Women in } \\
\text { control } \\
\text { group }\end{array}$ & $\begin{array}{l}\text { IOM } \\
\text { recommended } \\
\text { weight gain }(\mathbf{k g})\end{array}$ & $\begin{array}{l}\text { Weight gain in } \\
\text { study group } \\
(\mathbf{k g})\end{array}$ & $\begin{array}{l}\text { Weight gain in } \\
\text { control group } \\
(\mathbf{k g})\end{array}$ \\
\hline Underweight & 336 & 46 & 290 & $12.5-18$ & 11.8 & 14.3 \\
\hline Normal & 1054 & 76 & 978 & $11.5-16$ & 9.2 & 12.2 \\
\hline Overweight & 183 & 122 & 61 & $7-11.5$ & 11.2 & 11 \\
\hline Obese & 62 & 31 & 31 & $5-7$ & 12.3 & 9.5 \\
\hline Total & 1635 & 275 & 1360 & & & \\
\hline
\end{tabular}

Table 3: Comparison of gestational weight gain with IOM recommendations.

\begin{tabular}{|c|c|c|c|c|c|}
\hline $\begin{array}{l}\text { No. of women in each } \\
\text { category }\end{array}$ & $\begin{array}{l}\text { IOM recommenda- } \\
\text { tions }(\mathbf{k g})\end{array}$ & $\begin{array}{l}\text { Weight gain according to } \\
\text { IOM recommendations }\end{array}$ & $\begin{array}{l}\text { Study } \\
\text { group }(\%)\end{array}$ & $\begin{array}{l}\text { Control } \\
\text { group }(\%)\end{array}$ & $P$ value \\
\hline \multirow{3}{*}{ Underweight, N=336 } & \multirow{3}{*}{$12.5-18$} & Below (122) & $15(12.2)$ & $107(87.7)$ & 0.5 \\
\hline & & Met (184) & $31(16.8)$ & $153(83.1)$ & 0.06 \\
\hline & & Beyond (30) & 0 & $30(100)$ & 0.2 \\
\hline \multirow{3}{*}{ Normal, N=1054 } & \multirow{3}{*}{$11.5-16$} & Below (316) & $31(9.8)$ & $285(90.1)$ & 0.03 \\
\hline & & Within (662) & $31(4.6)$ & $631(95.3)$ & 0.0001 \\
\hline & & Beyond (76) & $14(18.4)$ & $62(81.5)$ & 0.0001 \\
\hline \multirow{3}{*}{ Overweight, $\mathrm{N}=183$} & \multirow{3}{*}{$7-11.5$} & Below (30) & $15(50)$ & $15(50)$ & 0.07 \\
\hline & & Within (47) & $31(65.9)$ & $16(34)$ & 0.9 \\
\hline & & Beyond (106) & 76 (71.6) & $30(28.3)$ & 0.1 \\
\hline \multirow{3}{*}{ Obese, $N=62$} & \multirow{3}{*}{$5-7$} & Below (0) & 0 & 0 & - \\
\hline & & Within $(0)$ & 0 & 0 & - \\
\hline & & Beyond (62) & $31(50)$ & $31(50)$ & 0.01 \\
\hline
\end{tabular}

Table 4: Maternal and fetal complications in study and control group.

\begin{tabular}{|llll|}
\hline Complications & Study group $(\mathbf{n}=\mathbf{2 7 5})(\boldsymbol{\%})$ & Control group $(\mathbf{n}=\mathbf{1 3 6 0})(\boldsymbol{\%})$ & P value \\
\hline Preeclampsia & $138(50)$ & $30(2.2)$ & $<0.001$ \\
\hline Preterm deliveries & $15(5.5)$ & $60(4.4)$ & 0.4 \\
\hline PROM & $31(11.1)$ & $92(6.7)$ & 0.00001 \\
\hline IUGR & Nil & $91(6.7)$ & 0.0095 \\
\hline IUFD & $46(16.6)$ & Nil & 0.0001 \\
\hline Macrosomia & $152(55.5)$ & Nil & 0.0001 \\
\hline Polyhydramnios & $31(11.1)$ & 0 & 0.00001 \\
\hline NICU admissions & $138(50)$ & $15(1.1)$ & 0.0001 \\
\hline
\end{tabular}

\section{DISCUSSION}

Throughout the world, wide variations are found in prevalence of GDM depending upon the ethnicity, different living conditions, socioeconomic levels, dietary habits and criteria used for diagnosis. Worldwide one in 10 pregnancies is associated with diabetes, $90 \%$ of which are GDM. Indian data is more alarming with around one in every five pregnancy being GDM. ${ }^{5}$

In our study, out of 1635 women 275 were diagnosed GDM with an incidence of $16.8 \%$ using DIPSI criteria.
Based on different Indian studies, prevalence of GDM ranges from $0.6 \%$ to as high as $40 \% .^{6-8}$

Raised BMI (>25) at first visit is associated with higher chances of GDM.9-12 Our study exhibited maximum weight gain during 13 to 26 weeks. This coincides with the physiological timing of developing insulin resistance in pregnancy.

Meta-analysis by Najafi et al in 2018 reported 4\% increased risk of GDM with per unit increase in BMI. ${ }^{13}$ Similar meta-analysis in 2020 including 11 articles offered 
convincing evidence of relationship between high BMI and GDM. ${ }^{14}$

Based on IOM guidelines, two meta-analyses including over one million pregnant women reported $37 \%$ (95\% CI: $33-41 \%$ ) and $47 \%$ women had excessive gestational weight gain respectively. ${ }^{15-17}$ Our study endorses their results with the startling finding of high prevalence of excessive weight gain among obese and overweight women. In the study group, 50\% women with BMI $>25$ crossed their weight gain limits and subsequently developed GDM. Many studies favour similar results. ${ }^{12,18-}$ 20 Moreover, in our study the weight gain in early gestational age (13-26 weeks) is much higher than weight gain in late gestational age (26-34 weeks). ${ }^{19}$ Our study endorses the results of study by Zhong et al. ${ }^{21}$ In a similar study by Boriboonhirusarn et al weight gain of more than $7 \mathrm{~kg}$ in second trimester increased the risk of GDM. ${ }^{22}$ Prime concern is the risk of weight retention and developing DM type 2 in such women. ${ }^{23}$ This adds to the Indian diabetic pool which is expected to cover 101.2 million of Indian population by $2030 .{ }^{24} \mathrm{We}$ also found mean BMI of the women in the study group 3-4\% higher throughout pregnancy. This is similar to the results of study by MacDonald et al. They concluded that an upward weight gain trajectory beyond IOM recommendations in first trimester is associated with GDM in most BMI categories. ${ }^{19}$

Considering the interrelationship between raised BMI, excessive gestational weight gain and risk of GDM, we also studied the role of genetic predisposition. $27.7 \%$ women who developed GDM had a diabetic first degree relative. Study by Nair et al and Rajput et al on Indian women showed family history of diabetes as a significant risk factor $(\mathrm{p}<0.001){ }^{25,26}$

Both obesity and GDM badly affect feto-maternal health. We found some health issues related to GDM like, preeclampsia, preterm deliveries, premature rupture of membranes (PROM), intrauterine fetal death (IUFD), intrauterine growth restriction (IUGR) and polyhydramnios. In our study, odds of preeclampsia in study group was higher (OR $>>1)$ than the control. Similar results were described in a registry-based study from Tanzania by Mrema et al. ${ }^{27}$ They reported a strong association between raised BMI and preeclampsia. Rahman et al conducted a meta-analysis in 2015 including 42 studies. They concluded that overweight and obese mothers were at higher odds of GDM, pre-eclampsia and caesarean delivery. ${ }^{28}$ Various Indian and international studies depicting similar results were found. ${ }^{29-31}$ Also, we found higher odds for preterm, macrosomia, IUFD and NICU admissions in study group. In a cohort study by Doi relation between high maternal BMI and pregnancy outcome was studied. The results showed odds of pre-term delivery were higher in overweight and obese women. ${ }^{32}$ In contrast to women in control group, odds for macrosomia were highly significant in GDM women. An Indian study by Bhavadharini et al concluded that obese and overweight women during pregnancy were at higher risk of delivering macrosomic baby. ${ }^{33,34}$ Studies by Doi et al, $\mathrm{Su}$ et al, Castillejos et al, and Melchor et al also endorses similar results. ${ }^{29,30-32,35}$

\section{CONCLUSION}

Obesity is the new pandemic worldwide. India is already known as the diabetic capital of the world. We are witnessing a threatening rise in GDM. We have to make an effort to closely monitor the GWG. An adequate GWG is an important milestone of pregnancy. Awareness needs to be reiterated amongst health care providers. Though GDM is genetically influenced, much depends on recommended weight gain during pregnancy. An increased BMI especially in early pregnancy is found to be associated with adverse pregnancy outcome and has a lifelong impact not only on the neonate but till its maturity to an adult.

Thus, compliance of recommended weight gain especially has a strong impact on the fetal outcome. Moreover, in a country like ours, weight gain can be easily monitored even in smaller clinics, as it does not require very sophisticated equipment. In addition, importance of prepregnancy counselling must be included wherever possible for loss or gain of appropriate weight even prior to pregnancy to prevent adverse outcome.

GWG is the single, simple and very vital parameter in having a good feto-maternal outcome in women with GDM.

\section{ACKNOWLEDGMENTS}

Authors would like to acknowledge all women and staff of Pt. J. N. M. Medical College and DRBRAMH, Raipur, Chhattisgarh who participated in this study for their cooperation.

\section{Funding: No funding sources}

Conflict of interest: None declared

Ethical approval: The study was approved by the Institutional Ethics Committee

\section{REFERENCES}

1. Kappil M, Wright RO, Sanders AP. Developmental origins of common disease: epigenetic contributions to obesity. Annu Rev Genomics Hum Genet. 2016;17(1):177-92.

2. Arora P, Aeri BT. Gestational Weight Gain among Healthy Pregnant Women from Asia in Comparison with Institute of Medicine (IOM) Guidelines-2009: A Systematic Review. J Pregnancy. 2019;3849596.

3. Rasmussen KM, Yaktine AL. Weight gain during pregnancy: re-examining the guidelines. Institute of Medicine and National Research Council of the National Academies. The National Academies Press, Washington. 2009. 
4. Seshiah V, Das AK, Balaji V, Joshi SR, Parikh MN, Gupta S, et al. For Diabetes in Pregnancy Study Group. DIPSI Guidelines.

5. Ministry of health and family welfare, Govt of India. Maternal Health Division. Diagnosis and management of Gestational Diabetes technical guidelines. 2018.

6. Shridevi AS, Prabhudev P, Madusoodana RB. A clinical study of prevalence of gestational diabetes mellitus and associated risk factors at a tertiary care centre in Karnataka, India. Int J Reprod Contracept Obstet Gynecol. 2017;4(6):1840-5.

7. Mithal A, Bansal B, Kalra S. Gestational Diabetes in India: Science and society. Indian $\mathrm{J}$ Endocrinol Metab. 2015;19(6):701-4.

8. Bhatt AA, Dhore PB, Purandare VB, Sayyad MG, Mandal MK, Unnikrishnan AG. Gestational diabetes mellitus in rural population of Western India-Results of a community survey. Indian J Endocrinol Metab. 2015;19(4):507-10.

9. Martin KE, Grivell RM, Yelland LN, Dodd JM. The influence of maternal BMI and Gestational diabetes on pregnancy outcome. Diabetes Res Clin Pract. 2015;108(3):508-13.

10. Larrabure-Torrealva, G.T., Martinez, S., LuqueFernandez, M.A., Sanchez S.E, Mascaro P.A., Ingar $\mathrm{H}$ et al. Prevalence and risk factors of gestational diabetes mellitus: findings from a universal screening feasibility program in Lima, Peru. BMC Pregnancy Childbirth 18, 303.

11. Hashim M, Radwan H, Hasan H, Obaid R S, Ghazal Al H, Hilali Al M et al. Gestational weight gain and gestational diabetes among Emirati and Arab women in the United Arab Emirates: results from MISC cohort. BMC Pregnancy and childbirth 2019; 19:463.

12. Kampmann U, Madsen LR, Skajaa GO, Iversen DS, Moeller N, Ovesen P. Gestational diabetes: a clinical update. World J Diabetes. 2015;6(8):1065.

13. Najafi F, Hasani J, Izadi N, Hashemi-Nazari SS, Zahra Namvar, Mohammadi S, et al. The effect of prepregnancy body mass index on the risk of gestational diabetes mellitus: A systematic review and doseresponse meta-analysis. Obesity reviews. 2018;20(3):225-32.

14. Yao D, Chang Q, Wu QJ , Gao SY, Zhao H, Liu YS, et al. Relationship between maternal central obesity and the risk of gestational diabetes mellitus: A systematic review and meta-analysis of cohort studies. J Diabetes Res. 2020;6303820.

15. Goldstein RF, Abell SK, Ranasinha S, Misso M, Boyle JA, Black MH, et al. Association of gestational weight gain with maternal and infant outcomes: A systematic review and meta-analysis. JAMA. 2017;317(21):2207-25.

16. Viecceli C, Remonti LR, Hirakata VN, Mastella LS, Gnielka V, Oppermann MLR, et al. Weight gain adequacy and pregnancy outcomes in gestational diabetes: a meta-analysis. Obes Rev. 2017;18(5):56780.
17. Johnson JL, Farr SL, Dietz PM, Sharma AJ, Wanda $\mathrm{D}$, Barfield A, et al. Trends in gestational weight gain: the pregnancy risk assessment monitoring system, 2000-2009. Am J Obstet Gynecol. 2015;212:806:1-8.

18. Banagala BGCSM, Karunarathne M. The relationship of gestational weight gain and development of gestational diabetes mellitus. Sri Lanka J Obstet Gynecol. 2019;41:104-10.

19. MacDonald SC, Bodnar LM, Himes KP, Hutcheon JA. Patterns of gestational weight gain in early pregnancy and risk of gestational diabetes. Epidemiol. 2017;28(3):419-27.

20. Dimitriadou D, Mintziori G, Neofytidou O, Mousiolis A, Kotsa K, Kazakos K, et al. Compliance with gestational weight gain in women with gestational diabetes mellitus. Endocrine Abstracts. 2019;63:600.

21. Zhong C, Li X, Chen R, Zhou X, Liu C, Wu J, et al. Greater early and mid-pregnancy gestational weight gain are associated with increased risk of gestational diabetes mellitus: A prospective study. Clin Nutr ESPEN. 2017;22:48-53.

22. Boriboonhirusarn D. Second trimester weight gain more than $7 \mathrm{~kg}$ increases the risk of gestational diabetes after normal first trimester screening. J Obstet Gynecol Res. 2016;43(3):462-7.

23. Rong Ke, Yu K, Han X, Szeto IMY, Qin X, Wang J, et al. Pre-pregnancy BMI, gestational weight gain and post-partum weight retention: a meta-analysis of observational studies. Public Health Nutr. 2015;18(12):2172-82.

24. Whiting DR, Guariguata L, Weil C, Shaw J. IDF Diabetes Atlas: Global estimates of the prevalence of diabetes for 2011 and 2030, Diabetes Research and Clinical Practice. 2011;94(6):311-21.

25. Nair VG, Sandhu GS, Biswas M, Bhalla R. Evaluation of the incidence and outcome of gestational diabetes mellitus using the current international guidelines for diagnosing hyperglycemia in pregnancy. Int I Reprod Contracept Obstet Gynecol. 2016;5(10):3361-6.

26. Rajput M, Bairwa M, Rajput R. Prevalence of gestational diabetes mellitus in rural Haryana: A community-based study. Indian J Endocrinol Metab. 2014;18(3):350-4.

27. Mrema D, Lie RT, Ostbye T, Mahande MJ, Daltveit AK. The association between pre pregnancy body mass index and risk of preeclampsia: a registry-based study from Tanzania. BMC Pregnancy Childbirth. 2018;18:56.

28. Rahman MM, Abe SK, Kanda M, Narita S, Rahman MS, Bilano V, et al. Maternal body mass index and risk of birth and maternal health outcomes in low-and middle- income countries: a systematic review and meta-analysis. Obes Rev. 2015;16(9):758-70.

29. Castillejos AB, Gomez-Salgado J, RodriguezAlmagro J, Ortiz-Esquinas I, Hernandez-Martinez A, et al. Relationship between maternal body mass index and obstetric and perinatal complications. J Clin Med. 2020;9(3):707.

30. Melchor I, Burgos J, Aiartzaguena A, Gutierrez J, Melchor JC. Effect of maternal obesity on pregnancy 
outcomes in women delivering singleton babies: a historical cohort study. J Perinat Med. 2019;47(6):625-30.

31. Shah PM, Chatrapati AK, Bandekar PK. Retrospective study on the effect of Body Mass Index (BMI) on maternal and neonatal outcome. Int J Reprod Contracept Obstet Gynecol. 2018;7(3):10703.

32. Doi L, Williams AJ, Marryat L, Frank J. Cohort study of high maternal body mass index and the risk of adverse pregnancy and delivery outcomes in Scotland. BMJ Open. 2020;10(2):026168.

33. Bhavadharini B, Anjana RM, Deepa M, Jayashree G, Nurtya S, Shobana M, et al. Gestational weight gain and pregnancy outcomes in relation to body mass index in Asian Indian Women. Indian J Endocr Metab. 2017;21:588-93.

34. Gavhane S, Sangle A, Gaikwad R. Relation of Birth weight with maternal pre-pregnancy weight and weight gain during pregnancy. 2018;6(3):9-12.

35. Su XJ, Huang SJ, Du QL. Pre pregnancy overweight and obesity are associated with an increased risk of preterm birth in Chinese women. Obes Facts. 2020;13(2):237-44.

Cite this article as: Singh A, Kujur A, Roy A. Body mass index and gestational weight gain in pregnant women with gestational diabetes and its relation with adverse maternal and fetal outcome. Int J Reprod Contracept Obstet Gynecol 2020;9:4256-61. 